\title{
X-ray Diffraction Analysis of Nano Sized Seed Powder of White Colored Germplasm of Velvet Bean (Mucuna pruriens), an Underutilized Wild South Indian Food Legume
}

\author{
M Marimuthu $^{1 *}, \mathrm{M} \mathrm{Venkatesh}^{1}, \mathrm{M}$ Poongodi ${ }^{2}$ \\ ${ }^{1}$ Nutraceutical Chemistry Lab, Department of Food Process Engineering,School of Bioengineering, SRM University, Kattankulathur-603203, \\ Tamil Nadu, India \\ ${ }^{2}$ Department of Computer Science Engineering, Bhajarang Engineering College, Veppampattu- 602 024, Thiruvallur, Tamil Nadu, India \\ * Corresponding author: Marimuthu M (marimtu@gmail.com), Tel: +9196008 58569
}

\begin{abstract}
The present investigation was carried out to characterize starches, particle size, morphology index and structural properties from velvet bean seed powder. Structural characteristics of starch extracted from these nano sized seed powder was evaluated using X-ray diffraction (XRD) and analyzed particles size, morphology, and degree of Crystallinity. From our XRD analysis, starch presented a C-type XRD pattern and crystallite size of $38.26 \AA$. The particle size was found to be 15 to $41 \mathrm{~nm}$. Morphology index (MI) ranged from 0.5 to 0.73 . It is observed that MI has direct relationship with particle size and indirect relationship with specific surface area.The morphology and particle size was confirmed by XRD, Transmission Electron microscopy (TEM) which showed formation of well-dispersed gold nanoparticles in the range of 14 to $43 \mathrm{~nm}$ with monodisperse in nature. These starch nanocrystals could be potential precursors to nanocomposites and nanoparticle-based copolymers.
\end{abstract}

Keywords: Crystallinity Degree, Nano particles Morphology Index, Velvet bean seed, XRD

Citation: M Marimuthu et al. X-ray Diffraction Analysis of Nano Sized Seed Powder of White Colored Germplasm of Velvet Bean (Mucuna pruriens), an Underutilized Wild South Indian Food Legume. Nano Biomed. Eng. 2013, 5(3),121-126. DOI: 10.5101/nbe.v5i3.p121-126.

\section{Introduction}

Mucuna pruriens var. utilis commonly known as velvet bean or cow-itch is a self-pollinated tropical legume known for its medicinal properties and reported to be indigenous to India and china. The velvet bean is consumed and promoted by smallholder farmers in Africa, South America and South Asia as a green manure or a cover crop $[1,2]$ because this plant possess valuable medicinal properties and it has been studied for various activities like itching [3], antioxidant [4], anti-diabetic [5] anti-neoplastic, anti-epileptic, antimicrobial [6], aphrodisiac [7] and antihelmintic activity [8]. Mucuna pruriens has also been shown to be neuro protective and as a fertility agent (in men). It also has analgesic and antiinflammatory activities [9]. The velvet bean is rich in protein (23-35\%) and has a nutritional quality comparable to that of other pulses like soybean, rice bean and lima bean $[10,11]$. It is considered a viable source of dietary proteins $[12,13]$ due to its high protein concentration (23-
$35 \%$ ) in addition its digestibility, which is comparable to that of other pulses such as soybean, rice bean, and lima bean [11]. Legume proteins are used as ingredients primarily to increase nutritional quality and to provide a variety of functional properties, including desirable structure, texture, flavour, and colour characteristics in formulated food products. It is therefore regarded a good source of food.

Starch is a polysaccharide originated from plants as renewable resources. Legumes contain about $60 \%$ carbohydrates in which starch constitutes the major portion [14]. Modified starches played a significant role in fat-reduction products, fat replacers in dairy applications, baking applications and meat applications [15]. Starch, the principal carbohydrate constituent of majority of plant materials, merits a detailed investigation to understand better its biochemical and functional 
characteristics as well as variations [16]. Starch is considered of commercial importance due to its high industrial demand as an ingredient for a variety of processed foods [17]. Applications of starch in food systems are primarily governed by gelatinization, pasting, solubility, swelling and digestibility properties. Starch is a biocompatible polymer. The use of synthetic polymer matrix materials often goes along with detrimental effects on incorporated drug during manufacturing of formulations or during the degradation of the polymers after application [18].

Legume starches have been characterized by a high amylose content of 24-65\% [19]. The amylose content of the starch varies with the botanical source of the starch and is affected by the climatic conditions and soil type during growth [20]. The activities of the enzymes involved in starch biosynthesis may be responsible for the variation in amylose content among the various starches [21] isolated in this work.

Mucuna starch can contribute greatly to the textural properties of many foods and in industries as a thickener, gelling agent and bulking agent. X-ray diffraction (XRD) pattern is mainly showing the properties of starch. For the first time, XRD investigations of the nano sized particles of velvet bean seed are recorded. The objective of the study was to investigate the type of starch, particle size, gold nano particle formation, morphology index and structural properties from velvet bean seed powder.

\section{Material and Methods}

\subsection{Powder preparation}

Velvet bean (Mucuna pruriens) seeds were collected from Western Ghats at Tirunelveli district, Tamilnadu, India. The seeds were cleaned and sun dried for 10 days. For these experimental purposes, $100 \mathrm{mg}$ dried seeds were put in a 3 mixer-grinder cum blender which having 550 watts, $17000 \mathrm{rpm}$ rotating speed electrical motor. The seeds were grounded and crushed well and uniformly for 15 minutes with utmost precaution to avoid any contamination and made them as nano-sized powder. The powdered materials were packed in plastic pouches and stored in normal room temperature until use.

\subsection{XRD analysis}

XRD analysis of the prepared sample of seed nanoparticles was done using a X'pert PRO of PANalytical diffractometer, $\mathrm{Cu}-\mathrm{K} \alpha \mathrm{X}$-rays of wavelength $(\lambda)=1.54056$ $\AA$ and data was taken for the $2 \theta$ range of $10^{\circ}$ to $80^{\circ}$ with a step of $0.02^{\circ}$. XRD analysis gave Size and degree of crystalline of the particles. Its structural characterizations were studied and results confirmed the nano sized seed powder. This analysis was done by Department of Nano science and technology, SRM University.

\subsection{Extract preparation}

The solvent systems of methanol were used for extractions. Soxhlet and flask extraction procedures were adapted for extraction. $10 \mathrm{~g}$ of the powered seed samples were packed in muslin cloth and used for extraction by soxhlet apparatus at a temperature below the boiling temperature of each solvent. A portion of the powdered seed samples was soaked in the conical flask containing solvent, wrapped with aluminum foil and placed in shaker for 48 hours at $120-130 \mathrm{rpm}$. After 48 hours, the extracts were filtered using Whatman filter paper No: 1. Following that the solvent the residue was dissolved in sterile dimethylsulfoxide (DMSO-9:1) in $50 \mathrm{mg} / \mathrm{ml}$ concentration. The extract was filtered using 0.22 micro filters (Type GV-Millipore) and stored at $4^{\circ} \mathrm{C}$ for further study

\subsection{Gold nanoparticle analysis}

$1 \mathrm{mM}$ solution of $100 \mathrm{~mL}$ Chloroauric acid $(0.034 \mathrm{~g})$ at concentration of $1 \mathrm{mM}$ was prepared by dissolving DDW (100 mL), kept in a $250 \mathrm{~mL}$ Erlenmeyer flask. 100 $\mathrm{mL}$ of velvet bean $(0.060 \mathrm{~g})$ supernatant was added to the chloroauric acid solution. The $95 \%$ of the bioreduction of $\mathrm{AuCl}_{4}^{-}$ions occurred within 10min. The yellow colored solution which it turned purple red slowly, indicating the formation of gold nanoparticles. XRD measurement of the velvet bean gold nanoparticles was carried out on films of the respective solutions drop coated onto glass substrates on a Rich Seifert P3000 instrument operating at a voltage of $40 \mathrm{kV}$ and a current of $30 \mathrm{~mA}$ with $\mathrm{Cu} \mathrm{K \alpha 1}$ radiations.

\section{Results and discussion}

\subsection{XRD studies}

\subsubsection{Peak indexing}

The X-ray diffraction pattern of the velvet bean white colored seed powder nanoparticles is shown in Fig. 1. Indexing is the process of determining the size and shape of the unit cell given the peak positions in a diffraction pattern. The term gets its name from the assignment of Miller index labels to individual peaks. For most applications, the index labels are less important than are the unit cell length and angle parameters that provide the link between crystal properties and the diffraction pattern. The indexing process of velvet bean powder diffraction pattern is done and Miller Indices (hkl) to each peak is assigned. The details are in Table 1. A number of Bragg reflections which is correspond to the peak reflection as follows, 111, 200, 211, 311 and 322, respectively. The diffraction peaks are broad which is indicating the crystallite size is very small. The size of the velvet bean seed nanoparticles estimated from Debye-Scherrer formula is was found to be 15 to $41 \mathrm{~nm}$.

\subsubsection{XRD-Particle size calculation}

Particle size and size distribution are the most important characteristics of nanoparticle systems. They determine the in vivo distribution, biological fate, toxicity and the targeting ability of nanoparticle systems. Many studies have demonstrated that nanoparticles of submicron size have a number of advantages over micro 
particles as a drug delivery system [22]. From this study, considering the peak at degrees, average particle size has been estimated by using Debye-Scherrer formula.

$$
\mathrm{D}=(0.9 \lambda) /(\beta \cos \theta)
$$

Where ' $\lambda$ ' is wave length of $X$-Ray $(0.1541 \mathrm{~nm})$, ' $\beta$ ' is FWHM (full width at half maximum), ' $\theta$ ' is the diffraction angle and ' $\mathrm{D}$ ' is particle diameter size. The calculated particle size details are in Table 2 . The value of $d$ (the interplanar spacing between the atoms) is calculated using Bragg's Law.

$$
2 \mathrm{~d} \sin \theta=\mathrm{n} \lambda
$$

\subsubsection{XRD-Degree of crystallinity}

Degree of crystalline is perhaps the most common quantitative application of XRD. When the amorphous phase is present or suspected, XRD can be used to characterize the material and determine the ratio of crystalline to amorphous material in the sample. Starch is an important polysaccharide reserve in legumes. It consists of two main components, amylose and amylopectin. It is a semi-crystalline polymer in which amylose forms the crystalline region and amylopectin forms the amorphous region [23]. The main crystalline peaks in the XRD pattern are attributed to the crystalline peaks of starch. It is generally agreed that the peak breadth of a specific phase of material is directly proportional to the mean crystallite size of that material. Quantitatively speaking, sharper XRD peaks are typically indicative of high nano crystalline nature and larger crystallite materials. An empirical method of Segal for crystalline degree calculation is below [24].

$$
\mathrm{C}_{\mathrm{rl}}=100\left(\mathrm{I}_{002}-\mathrm{I}_{\text {Amorph }}\right) / \mathrm{I}_{002}
$$

Where $C_{r I}$ is the degree of crystallinity, $I_{002}$ is the maximum intensity of the lattice diffraction and $\mathrm{I}_{\mathrm{Amorph}}$ (311) is the intensity diffraction at $31^{\circ} 42 \theta$ degrees. Peak intensity details are enumerated in Table 3 . CrI is calculated using the Segal et al. equation .The final value is well in agreement with amylose content of starch of legumes seed powder and amylose occupies the crystalline parts of starch.

\subsubsection{XRD-Starch analysis}

Its XRD pattern is the "fingerprint" of the crystal structure within starch grains. According to the characteristic X-ray diffraction lines, the crystal structure of starch can be divided into three types, including $A$, $\mathrm{B}$ and $\mathrm{C}$ type. Of these A, B, and C-type are the crystal structures of natural starch. The crystalline patterns of velvet bean legume starches as determined by XRD are shown in Fig. 1. Starch can be classified into A, B and C forms [25]. All legume starches showed a characteristic C-type diffraction pattern, which actually consisted of a mixture of A and B-type crystalline structure [26]. A form starch is mainly present in cereal starches, such as maize starch and wheat starch. The XRD patterns of these starches give the stronger diffraction peaks at around 15, 17,18 and $23^{\circ}$. The B form starch is usually available in tuber starch such as potato and this type of starch gives the strongest diffraction peak at $17^{\circ} 2 \theta$. The $\mathrm{C}$ pattern starch is a mixture of both A and B types, such as smooth seeded pea starch and various bean starches. A C-type $\mathrm{X}$-ray pattern for different legume starches has been previously reported $[27,28]$ XRD pattern may depend on starch origin as well as environmental growth condition [29] It shows diffraction peaks at around $15^{\circ}, 17^{\circ}, 23^{\circ}$, $31^{\circ}$ and $38^{\circ}$. These are indicating the presence of type-C starch in the seed flour of velvet bean.

\subsubsection{XRD-Morphology index}

The use of legumes seed powder as a raw material is derived from its unique structural, physical and chemical properties, which are reflected by its hardness, surface properties, particle size and morphology. A XRD morphology index (MI) is developed from FWHM of $\mathrm{X}$-Ray diffraction data to understand this relationship. Morphology index (MI) relates the FWHM of two peaks to its particle morphology (peak having highest FWHM and a particular peak's FWHM for which MI is calculated). Generally, highest FWHM peak MI is 0.5 because the MI is derived from the single peak only. MI is obtained using the following equation. Experimental velvet bean seed powder MI range is from 0.50 to 0.72 and the details are presented in Table-4. It is correlated with the particle size. The result shows that morphology index has direct relationship with particle size. The results are shown in Fig. 2.

$$
\mathrm{C}_{\mathrm{rI}}=\mathrm{FwHMh} /\left(\mathrm{FwHMh}_{\mathrm{w}}+\mathrm{FwHMp}_{\mathrm{w}}\right)
$$

Where, M.I. is morphology index, FWHMh is highest FWHM value obtained from peaks and FWHMp is value of particular peak's FWHM for which M.I. is to be calculated.

\subsubsection{XRD-Specific surface area}

Specific surface area (SSA) is a material property. It is a derived scientific value that can be used to determine the type and properties of a material. It has a particular importance in case of adsorption, heterogeneous catalysis and reactions on surfaces.

$$
\mathrm{S}=6^{*} 10^{3} / \mathrm{Dp} \rho
$$

Where $\mathrm{S}$ is the specific surface area, $\mathrm{Dp}$ is the size of the particles, and $\rho$ is the density of sample. Mathematically, SSA can be calculated using these formulas. The value of density is $0.60 \mathrm{~g} / \mathrm{cm}^{3}$ which noted from the studies of [30]. The theoretical calculation of SSA of velvet bean seed nanoparticles are presented in Table 5. It is correlated with morphological index. It is observed that SSA has indirect relationship with M.I shown in Fig. 3.

\subsubsection{Gold nanoparticles analysis}

The biosynthesis of gold nanoparticle of velvet bean seed was carried out in this work. The addition of seed 
extract to $1 \mathrm{mM}$ aqueous $\mathrm{HAuCl}_{4}$ resulted in the color change to pink-ruby red after $10 \mathrm{~min}$ of reaction due to the production of gold nanoparticles. These color changes arise because of the excitation of surface plasmon vibrations with the gold nanoparticles [31].

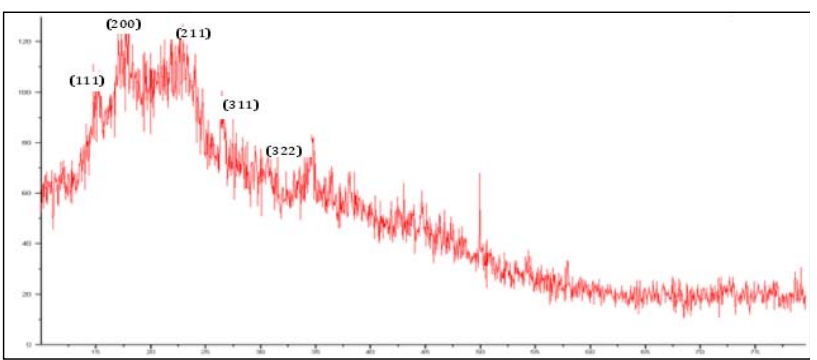

Fig. 1 XRD showing Peak Indices \& $2 \theta$ Positions in velvet bean (white colored seed).

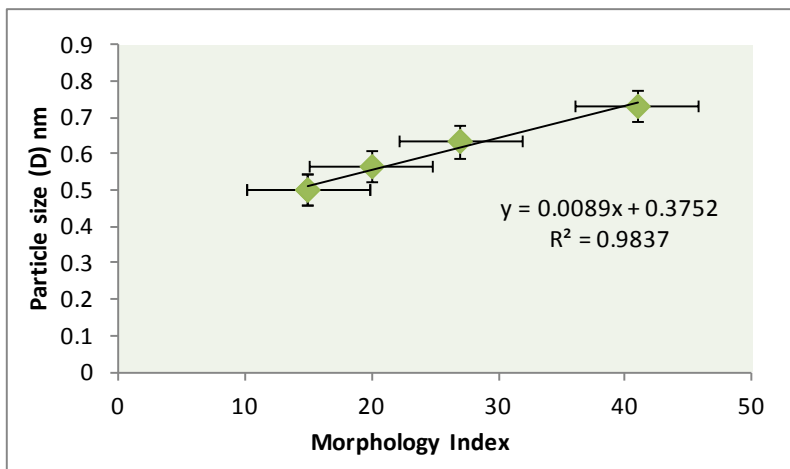

Fig. 2 Morphological Index versus Particle Size.

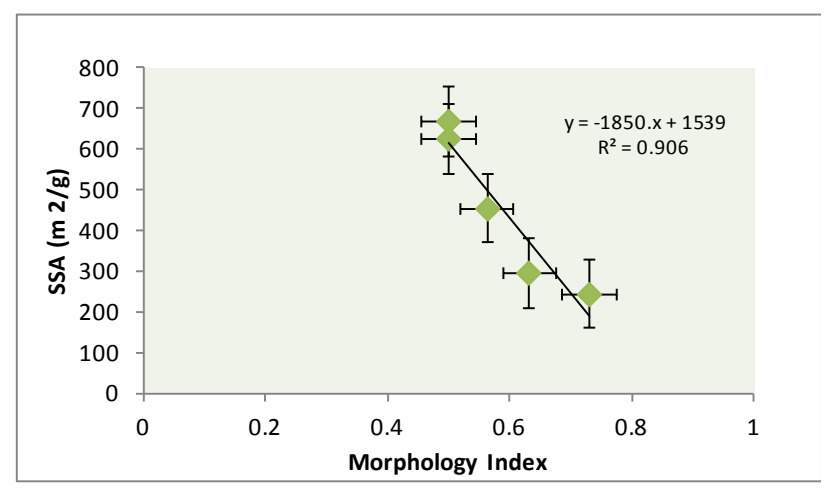

Fig. 3 Morphological Index versus Specific Surface Area.

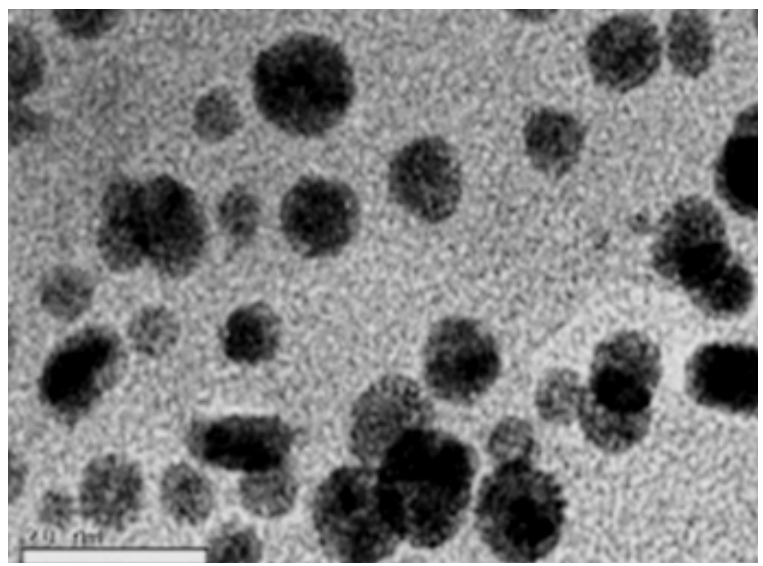

Fig. 4 Transmission electron micrograph image of gold nanoparticles formed by velvet bean seed extract.
XRD pattern obtained has been represented in Fig. 1 . XRD study was used to confirm the crystalline nature of the particle. The XRD patterns thus clearly show that the gold nanoparticles formed by the bioreduction of $M$. pruriens seed extract. The XRD analysis showed intense peaks corresponding to (111), (200) and (211) Bragg's reflection based on the FCC structure of gold nanoparticles. The broadening of Bragg's peaks indicates the formation of nanoparticle. The size of the nanoparticles was thus determined to be about $15 \mathrm{~nm}$ for gold nanoparticles. The mean size of gold nanoparticles was calculated using the Debye-Scherrer's equation by determining the width of the (111) Bragg reflection [32].

The morphology and size of as-formed gold nanoparticles were further determined by HR-TEM images. TEM image has shown well structured individual gold nanoparticles without aggregates. The images clearly show that the average size of the particles was found to be 14 to $42 \mathrm{~nm}$. The HR-TEM image showed that biosynthesized gold nanoparticles presented variable shape most of them were predominantly monodisperse in nature with some others having spherical shape in the micrograph (Fig. 4). Various magnifications of TEM images of gold nanoparticles is noted that the particles are of uniformed size ca. around $15 \mathrm{~nm}$. TEM analysis revealed that the synthesized nanoparticles are stable in solution over a period of one month at room temperature.

Table 1 Peak indexing from d-spacing in velvet bean (white colored seed)

\begin{tabular}{|c|c|c|c|c|}
\hline $2 \theta$ & $\mathrm{d}(\AA)$ & $1000 / \mathrm{d} 2$ & $(1000 / \mathrm{d} 2) / 10.6$ & $\mathrm{hkl}$ \\
\hline 15.210 & 5.821 & 29.503 & 3 & 111 \\
\hline 17.105 & 5.181 & 37.253 & 4 & 200 \\
\hline 23.005 & 3.863 & 66.983 & 6 & 211 \\
\hline 31.405 & 2.846 & 121.914 & 11 & 311 \\
\hline 38.500 & 2.363 & 178.99 & 17 & 322 \\
\hline
\end{tabular}

Table 2 The grain size of velvet bean (white colored seed powder)

\begin{tabular}{|c|c|c|c|c|}
\hline $2 \theta$ & hkl & $\begin{array}{c}\text { FWHM of peak } \\
(\beta) \text { radians }\end{array}$ & $\begin{array}{c}\text { Size of particle }(\mathrm{D}) \\
(\mathrm{nm})\end{array}$ & $\begin{array}{c}\mathrm{d} \text {-spacing } \\
(\mathrm{nm})\end{array}$ \\
\hline 15.210 & 111 & 0.00902 & 15 & 0.5821 \\
\hline 17.105 & 200 & 0.00334 & 41 & 0.5181 \\
\hline 23.005 & 211 & 0.00905 & 15 & 0.3863 \\
\hline 31.405 & 311 & 0.00702 & 20 & 0.2846 \\
\hline 38.120 & 322 & 0.00525 & 27 & 0.2363 \\
\hline
\end{tabular}

Table 3 Intensity of XRD Peaks in velvet bean (white colored seed)

\begin{tabular}{|c|c|c|c|c|c|}
\hline hkl & 111 & 200 & 211 & 311 & 322 \\
\hline $2 \theta$ of peak (deg) & 15.21 & 17.10 & 23.00 & 31.40 & 38.12 \\
\hline Heights (counts) & 36.00 & 100.5 & 67.01 & 62.04 & 41.04 \\
\hline Relative intensity (\%) & 34.12 & 98.46 & 65.02 & 60.00 & 39.12 \\
\hline
\end{tabular}

Table 4 Morphology Index of Nano-sized velvet bean (white colored seed) particles

\begin{tabular}{|c|c|c|}
\hline FWHM($(\beta)$ radians & Particle size(D)nm & Morphology Index \\
\hline 0.00902 & 15 & 0.500 \\
\hline 0.00334 & 41 & 0.730 \\
\hline 0.00905 & 15 & 0.500 \\
\hline 0.00702 & 20 & 0.563 \\
\hline 0.00525 & 27 & 0.632 \\
\hline
\end{tabular}

OdHo5T 100 
http://nanobe.org

Table 5 Morphology Index and specific surface area of Nanosized velvet bean particles

\begin{tabular}{|c|c|c|c|}
\hline $\begin{array}{c}\text { FWHM }(\beta) \\
\text { radians }\end{array}$ & $\begin{array}{c}\text { Particle size(D) } \\
\mathrm{nm}\end{array}$ & $\begin{array}{c}\text { Morphology } \\
\text { Index }\end{array}$ & SSA (m2/g) \\
\hline 0.00902 & 15 & 0.500 & 667 \\
\hline 0.00334 & 41 & 0.730 & 244 \\
\hline 0.00905 & 15 & 0.500 & 625 \\
\hline 0.00702 & 20 & 0.563 & 455 \\
\hline 0.00525 & 27 & 0.632 & 294 \\
\hline
\end{tabular}

\section{CONCLUSION}

The results of the study suggested that the morphological index, particle size and crystalline properties were observed from the flour of velvet bean starches. The digestibility of starch showed a significant correlation to particle size and morphological index. The results revealed that the structural property relationships have been established for native velvet bean starches. It yields the results that morphology index has direct relationship with particle size and indirect relationship with specific surface area. It is desirable that further studies be conducted on utilization of velvet bean starches in common food products like starch noodles and snack foods and their structural modification by chemical processes to make velvet bean starch more useful for the food processors. This seed extract was found appropriate for the synthesis of gold nanoparticles with monodisperse, stable and having size ranges from 14 to $43 \mathrm{~nm}$. The evidence of these nanocrystals and nano particle among other things, is a step towards meeting the quest for nanotechnology in all fields. This study suggests that velvet bean seed powder has a lot of potential in food, pharmaceuticals, and bio-medicine, bio-nanotechnology industries.

\section{Acknowledgements}

We express our sincere gratitude to our Director, Dr. C. Muthamizhchelvan, Engineering and Technology and Dr. M. Vairamani, Dean, School of Bioengineering, SRM University for their continuous support and encouragement towards this study.

\section{References}

1 Buckles D. Velvet bean. A "new" plant with a history. Economic Botany. 1995; 49(1): 13- 45 .

2 Ezeagu IE., Maziya-Dixon B., Tarawali G.Seed characteristics and nutrient and antinutrient composition of 12 Mucuna accessions from Nigeria. J. Trop. Subtrop. Agroecosysytems. 2003; 1: 129-140.

3 Armstrong D., Arcy RMI., Keela CA., Maikhana M .Observation of chemical excitants of cutaneouspain in man J.Physiol.1953; 12:351-376

4 Rajeshwar Y., Kumar GP, Gupta M., Maunder UK. In vitro antioxidant activities of methanol extract of Mucuna pruriens seeds Euro Bull Drug Res. 2005b; 1:31-39.

5 Akhtar MS., Quereshi AO., Iqbal J. Antidiabetic evaluation of Mucuna pruriens lunin seed J.Palc Med. Assoc. 1990;40(7):174- 50

6 Sathiyanarayanan L., Arulmozhi S. Mucuna pruriens a comprehensive review Phamracog. Rev.2007;1(1): 157-162.

7 Rajendran V., Joseph T., David J. Mucuna pruriens decreases sexual activity in female rats Indian Drugs.2007; 34(3):136-139.

8 Jalalpure SS., Alagawadi KR., Mahajanshelti CS. In Vitro antihelmintic property of various seed oils against pheritimapos- thuma Ind J Pharm. Sci.2007; 69:158-160.

9 Hishika R., Shastry S., Shinde S., Gupta SS. "Preliminary, Phytochemical and Anti-inflammatory Activity of seeds of Mucuna pruriens. Indian journal of Pharmacol.1981;13(01):97-98.

10 Bressani R. Factors influencing nutritive value of food grain legumes: Mucuna in comparison to other grain legumes In: Flores (Eds). Mucuna as Food and feed. Current uses and the way forward. Proceedings of an International workshop held April 26-29, 2000. UDICCO, CIEPA and World Hunger Research Center-Tegucigalpa, Honduras.2000; 164-188.

11 Gurumoorthi P., Pugalenthi M., Janardhanan K. Nutritional potential of five accessions of a South Indian tribal pulse, Mucuna pruriens var utilis II. Investigations on total free phenolics, tannins, trypsin and chymotrypsin inhibitors, phytohaemagglutinins, and in vitro protein digestibility. Journal of Tropical and Subtropical Agroecosystems. 2003;1: 153-158.

12 Janardhanan K., Gurumoorthi P., Pugalenthi M. Nutritional potential of five accessions of a South Indian tribal pulse, Mucuna pruriens var. utilis. Part I. The effect of processing methods on the contents of L-Dopa, phytic acid, and oligosaccharides. Journal of Tropical and Subtropical Agro-ecosystems. 2003;1:141-152.

13 Pugalenthi M., Vadivel V., Siddhuraju P. Alternative food/feed perspectives of an under-utilized legume Mucuna pruriens. Utilis-A Review/ Linn. J. Plant Foods Human Nutr. 2003;60:201-218.

14 Sathe SK., Salunkhe DK. Functional properties of the great Norther bean (Phaseolus vulgraris L.) Protein emulsion, foaming, viscosity and gelation properties $J$. Food Sci.1981;46: 71-74.

15 Kunkpetoon D., Wang YJ. Characterization on of different starches oxidized by hypochlorite, Starch.2001; 53: 211-218.

16 El-faki HA., Desikachar HSR., Paramahans SV., Thavanathan RN. Physicochemical characteristics of starches from chickpea, cowpea and horse gram. Starch.1993; 35: 118-122.

17 Whitaker IR., Tannenbaum SR. Food protein. Wes port: AVI publishing company Inc, 1997; 291-301.

18 Reithmeier HJ., Herrmann, Gopferich A. Development and characterization of lipid micro particles as a drug carrier for somatostatin Int. J. Pharm. 2001; 218:133-143.

19 Hoover R., Sosulski F. Composition, structure, functionality and chemical modification of legume starches: a review. Canadian Journal of Physiology and Pharmacology.1991; 69: 79-92.

20 Asaoka M., Okuno K., Fuwa H. Effect of environmental temperature at the milky state on amylose content and fine structure of waxy and non-waxy endosperm starches of rice (Oryza sativa L.). Agricultural and Biological Chemistry.1985; 49: 373-376.

21 Krossmann J., Lloyd J. Understanding and influencing starch biochemistry. Critical reviews in Biochemistry and Molecular Biology.2000; 35: 141-196.

22 Panyam J., Labhasetwar V. Biodegradable nanoparticles for drug and gene delivery to cells and tissue. Adv Drug Deliv Rev. 2008; 55:329-47.

23 Esat Gumuskaya, Mustafa Usta and HuseyinKirci. The effects of various pulping conditions on crystalline structure of cellulose in cotton linters. Polymer Degradation and Stability.2003; 81: 559-564

24 Wang Shujun, Yu Jinglin and Gao Wenyuan. Use of X-Ray Diffractometry (XRD) for Identification of Fritillaria According to Geographical Origin. American Journal of Biochemistry and Biotechnology .2005; 1:199-203.

25 Zobel H.F. Starch crystal transformations and their industrial importance. Starch-Starke. 1988; 40:1-7.

26 Donald, AM. Understanding starch structure and functionality. In Eliasson AC (Ed.), Starch in food: Structure, function and applications Cambridge/New York: Wood head Publishing Limited/CRC Press LLC.2004; 156-184.

27 Hoove R., Ratnayake WS. Starch characteristics of black bean, chickpea, lentil, navy bean and pinto bean cultivars grown in Canada. Food Chemistry.2002; 78:489-498.

28 Ratnayake WS., Hoover R., Shahidi F., Perera C., Jane J. Composition, molecular structure and physicochemical properties of starches from four field pea (Pisumsativum L.) Cultivars. Food Chemistry.2001; 74:189-202.

29 Huang J., Schols HA, Soest JJG, Jin Z., Sulmann E., Voragen AGJ Physicochemical properties and amylopectin chain profiles of 
Article

cowpea, chickpea and yellow pea starches. Food Chemistry. 2007; 101:1338-134.

30 Uma Sundaram, Gurumoorthi P. Studies on physical and chemical properties of velvet bean, an underutilized wild food legume, Engineering Technology in India.2012; 3(1):42-47.

31 Mulvaney P. Surface Plasmon spectroscopy of nanosized metal particles; Langmuir.1996;12,788-800.

32 Borchert H., Shevchenko E.V., Robert A., Mekis I., Kornowski A., Grubel G. Langmuir.Determination of nanocrystal sizes: a comparison of TEM, SAXS, and XRD studies of highly monodisperse CoPt3 particles.2005; 21:1931-6.

Copyright:(c) 2013 M Marimuthu, et al. This is an open-access article distributed under the terms of the Creative Commons Attribution License, which permits unrestricted use, distribution, and reproduction in any medium, provided the original author and source are credited. 